\title{
Health Risk Assessment on Drinking Water in Shenzhen, China
}

\author{
Guohong Liu, Ziqian Xu*, Jin Li, Guangwen Huang, Wei Wang \\ Shenzhen Center for Disease Control and Prevention, Shenzhen, China \\ Email: *liugh6610@163.com
}

How to cite this paper: Liu, G.H., Xu, Z.Q., Li, J., Huang, G.W. and Wang, W. (2018) Health Risk Assessment on Drinking Water in Shenzhen, China. Occupational Diseases and Environmental Medicine, 6, 71-80.

https://doi.org/10.4236/odem.2018.63006

Received: June 10, 2017

Accepted: July 28, 2018

Published: July 31, 2018

Copyright $\odot 2018$ by authors and Scientific Research Publishing Inc. This work is licensed under the Creative Commons Attribution International License (CC BY 4.0).

http://creativecommons.org/licenses/by/4.0/

\section{(c) (i) Open Access}

\begin{abstract}
Objectives: To conduct health risk assessment on drinking water in 2012 in Shenzhen of China. Methods: The water quality monitoring data on product water and pipe water in 2012 were collected and analyzed, and the risk evaluation models recommended by the U.S. environmental protection agency (US EPA) were employed, to perform adults and children's health risk assessments on the three kinds of genetic toxic substances such as hexavalent chromium, cadmium and arsenic and the 12 non-carcinogenic materials such as iron, manganese, lead, fluoride, volatile phenol, cyanide, mercury, ammonia nitrogen, nitrate, copper, zinc and selenium. Results: The results about water quality from the 150 factory samples and 207 peripheral water samples showed that the measured indicators in other water samples were accord with the National Health Standards (GB5749-2006) released by Ministry of Health of the People's Republic of China, except manganese level in one factory sample and the same index in one peripheral sample, and nitrate concentration in another water sample were out of limit, respectively. Namely, the total of 3 samples was disqualification. The adults and children's health risks (HI) on the 12 non-carcinogenic materials were $178.04 \times 10^{-8}$ and $249.96 \times 10^{-8}$ in the factor water samples, and $363.02 \times 10^{-8}$ and $509.66 \times 10^{-8}$ in the pipe samples, respectively. Lead in factory water and fluoride in peripheral water samples were the most serious harm in the all measured non-carcinogenic indicators. The adults and children's cancer risks (R) on the 3 genetic toxic substances were $25.60 \times 10^{-6}$ and $28.51 \times 10^{-6}$ in the factor water samples, and $23.47 \times 10^{-6}$ and $26.08 \times 10^{-6}$ in the pipe samples, respectively. Hexavalent chromium was the most damage among the three detected carcinogenic indicators. Therefore, the total adults and children's health hazard risks including the 3 carcinogenic and 12 non-carcinogenic substances were $27.38 \times 10^{-6}$ and $31.00 \times 10^{-6}$ in the factor water samples, and $27.10 \times 10^{-6}$ and $31.17 \times$ $10^{-6}$ in the pipe samples, respectively. Genetic toxic matters in drinking water
\end{abstract}


are the main hazard and more children's health risk than adults' risk. Conclusions: The health risk $(\mathrm{R})$ on the 15 kinds of chemicals in Shenzhen's municipal water supply was in the range of maximum acceptable risk levels (5.0 $\times 10^{-5} / \mathrm{a}$ ) recommended by the International Commission of Radiation Protection (ICRP). The results in this study indicate that the carcinogenic substances are greater risk comparing with the non-carcinogenic substances, and hexavalent chromium is the biggest carcinogenic risk, and lead and fluoride are the most non-carcinogenic risk, and the rather risk of children than adults.

\section{Keywords}

Urban Drinking Water, Carcinogenic Materials, Non-Carcinogenic Materials, Health Risk Assessment

\section{Introduction}

In recent years, serious environmental pollution events appeared occasionally around the world, which injured not only regional ecological environment but also human health [1] [2]. The harms resulted from environment pollution have been attaching more and more attention by governments and researchers [3] [4]. The greatest health risk for individual person per year in Ya'an City of Sichuan Province is caused by $\mathrm{Cr}$ (VI). The health risk of carcinogens is much higher than that of non-carcinogens: the greatest risk value due to non-carcinogen pollutants caused by fluoride (F), achieving $1.05 \times 10^{-8} / \mathrm{a}$ [5]. The same study in Tianjin results showed that the health risks of carcinogens, non-carcinogens were $3.83 \times 10^{-5}, 5.62 \times 10^{-9}$ and $3.83 \times 10^{-5}$ for total health risk respectively. The rank of health risk was carcinogen $>$ non-carcinogen. The rank of carcinogens health risk was urban $>$ new area $>$ rural area, chromium $(\mathrm{VI})>$ cadmium $>$ arsenic $>$ trichlormethane $>$ carbon tetrachloride. The rank of non-carcinogens health risk was rural area $>$ new area $>$ urban, fluoride $>$ cyanide $>$ lead $>$ nitrate. The total health risk level of drinking water in Tianjin was lower than that of ICRP recommended level $\left(5.0 \times 10^{-5}\right)$, while was between US EPA recommended level $\left(1.0 \times 10^{-6}-1.0 \times 10^{-4}\right)[6]$. Health risk assessment (HRA) is an evaluation method to correlate environmental pollution and human health by estimating probabilities of adverse effects. Water environmental health assessment is an important part of environmental health assessment, which is a quantitative method to calculate adverse effects on water pollutants [5] [7]. The typical HRA includes hazard identification, exposure assessment, dose-response analysis and risk assessment [8]. Although there are different uses in various countries, HRA is basically consisted of two parts, namely carcinogenic and non-carcinogenic risk evaluation [9]. Just as the following report, concentrations of the15 kinds of chemicals have been measured and their risk characteristics have been analyzed 
in this study.

\section{Materials and Methods}

\subsection{Experimental}

The chemical dataset of 49 different water monitoring sites 100 different peripheral water sampling sites according to terrain, landform, geology, hydrology, water system, drinking water sources, distributions of waterborne infectious disease and types of water supply project were obtained from the Health Directorate of Shenzhen for this study. Drinking water samples were collected every quarter in 2012, with a total of 150 factory samples and 207 peripheral samples according to correct sampling techniques to analyze their chemical contents. Detection indexes for these samples included iron, manganese, volatile phenol, cyanide, fluoride, lead, mercury, ammonia nitrogen, nitrate, copper, zinc, selenium, arsenic, cadmium and hexavalent chromium.

All filtered and acidified water samples were analyzed for trace metals (Fe, $\mathrm{Mn}, \mathrm{Pb}, \mathrm{Hg}, \mathrm{Cu}, \mathrm{Zn}, \mathrm{Se}, \mathrm{As}, \mathrm{Cd}$ ) (Table 1) using inductively coupled plasma mass spectrometer (ICP-MS, 7500 ce, USA). VP (Volatile Phenol, VP) and CN (Cyanide) were analyzed by flow injection analyzer (Futura 3, France). Ion chromatograph (ICS3000, USA) was employed to determine $\mathrm{F}$ and $\mathrm{NO}_{3}^{-} \cdot \mathrm{NH}_{3}^{-} \mathrm{N}$ and $\mathrm{Cr}^{6+}$ were detected by ultraviolet and visible spectrophotometer (1750, Japan). In view of data quality assurance, each sample was analyzed in triplicate and after every 10 samples two standard; one blank and another of $2.5 \mu \mathrm{g} / \mathrm{L}$ of respective metal were analyzed on atomic absorption. The reproducibility was found to be at 95\% confidence level, the relative standard deviations (RSD) were all less than 15\%, conforming to the requirements of the US EPA (RSD is less than 30\%). Therefore, the average value of each water sample was used for further interpretation.

\subsection{Health Risk Assessment}

According to the EPA's Comprehensive risk information database (IRIS) and International Agency for Research on Cancer (IARC), pollutants can be classified as carcinogens (also called no threshold compounds) and non-carcinogens (also called threshold compounds) [8] [10]. In this study, hexavalent chromium, arsenic and cadmium belonged to the no threshold compounds, iron, manganese, volatile phenol, cyanide, fluoride, lead, mercury, ammonia nitrogen, nitrate, copper, zinc and selenium compounds were attributed to the threshold compounds.

\subsubsection{Carcinogenic Risk Assessment}

Trace amounts of carcinogens produce very great harm to human health, which is generally considered by the gene toxicant quantitative risk assessment. $\mathrm{R}$ usually represents the risk of cancer caused by genetic toxic substances (arsenic, hexavalent chromium and cadmium). The calculation method of average personal annual risk of cancer is shown in Formulas (1)-(4):

$$
\mathrm{RT}=\Sigma \mathrm{Ri}
$$


Table 1. Detection parameters of chemicals in drinking water.

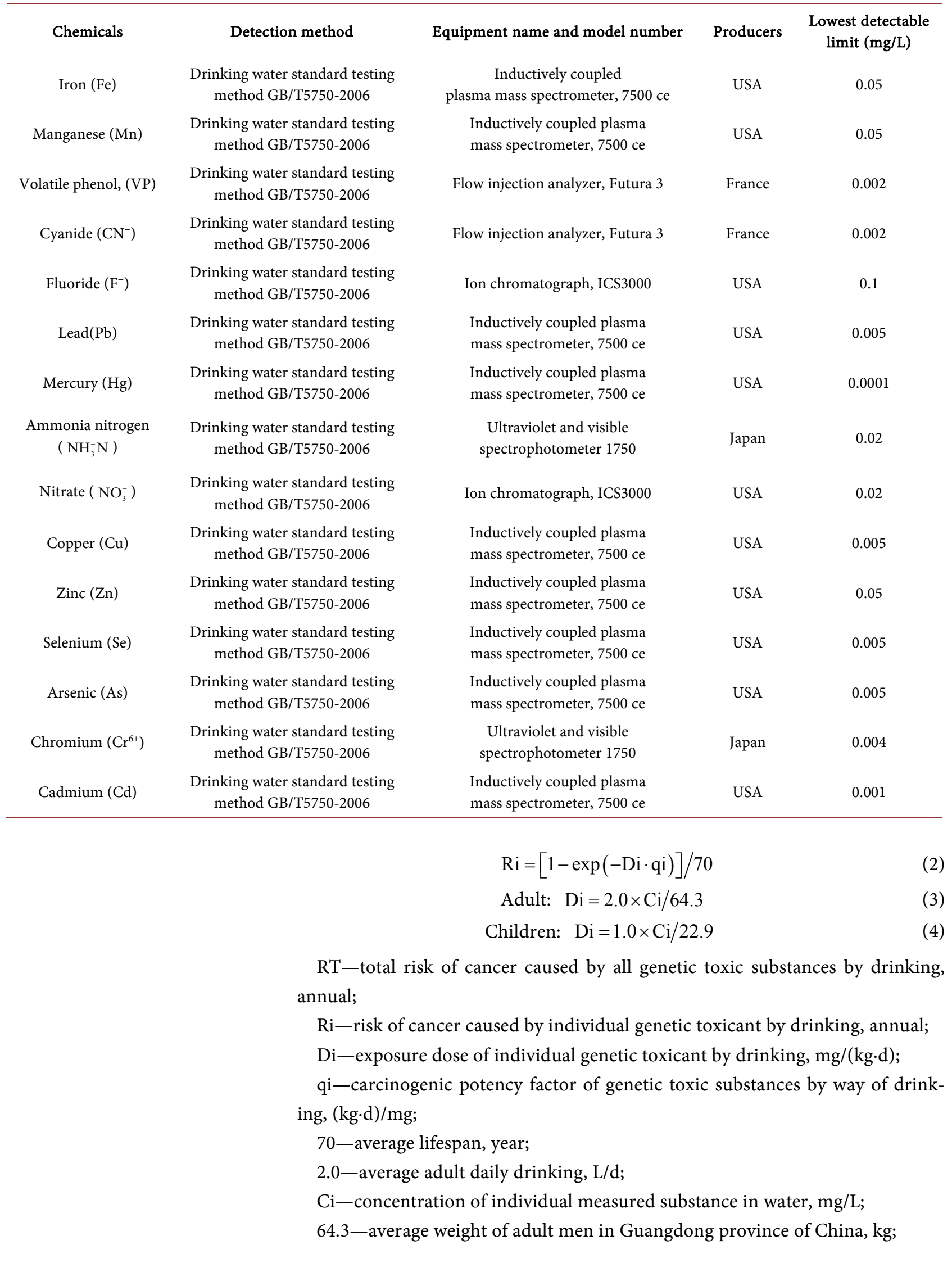


22.9-average weigh of children aged 7 years in Guangdong province, $\mathrm{kg}$.

\subsubsection{Non-Carcinogenic Risk Assessment}

Non-genetic toxicant quantitative risk assessment was used to evaluate risks of iron, manganese, volatile phenol, cyanide, fluoride, lead, mercury, ammonia nitrogen, nitrate, copper, zinc and selenium. Health risk index (HI) means average personal annual health risk values due to exposure to individual non-genetic toxicant. The calculation method is shown in Formulas (5) to (6):

$$
\begin{gathered}
\mathrm{HIi}=(\mathrm{Di} / \mathrm{RfDi}) \times 10^{-6} / 70 \\
\mathrm{HIT}=\Sigma \mathrm{HIi}
\end{gathered}
$$

$\mathrm{HIi}$-average personal health risk of individual non-genetic toxicant by drinking, annual;

HIT—average personal health risk of total non-genetic toxicants by drinking, annual;

$\mathrm{Di}$-exposure dose of individual non-genetic toxicantby drinking, $\mathrm{mg} /(\mathrm{kg} \cdot \mathrm{d})$, its calculation method is same as Formulas (3) and (4);

70-average lifespan, year;

$\mathrm{RfDi}-$ reference dose of individual non-genetic toxicant by drinking, $\mathrm{mg} /(\mathrm{kg} \cdot \mathrm{d})$;

$10^{-6}$ - a safety factor, dimensionless.

There are no basic data on exposure parameters in China at present, so we generally introduced the qi and RfDi, from USEPA to conduct risk assessment (see Table 2).

Table 2. Exposure parameters of chemicals in drinking water.

\begin{tabular}{cccc}
\hline Chemicals & Characters & qi $[(\mathrm{kg} \cdot \mathbf{d}) / \mathrm{mg}]$ & $\mathrm{RfD}[\mathrm{mg} /(\mathrm{kg} \cdot \mathbf{d})]$ \\
\hline Iron $(\mathrm{Fe})$ & Non carcinogens & $/$ & 0.3 \\
Manganese $(\mathrm{Mn})$ & Non carcinogens & $/$ & 0.14 \\
Volatile phenol, VP & Non carcinogens & $/$ & 0.3 \\
Cyanide $\left(\mathrm{CN}^{-}\right)$ & Non carcinogens & $/$ & 0.037 \\
Fluoride $\left(\mathrm{F}^{-}\right)$ & Non carcinogens & $/$ & 0.06 \\
Lead $(\mathrm{Pb})$ & Non carcinogens & $/$ & 0.0014 \\
Mercury $(\mathrm{Hg})$ & Non carcinogens & $/$ & 0.0003 \\
Ammonia nitrogen $\left(\mathrm{NH}{ }_{3}^{-} \mathrm{N}\right)$ & Non carcinogens & $/$ & 0.97 \\
Nitrate $\left.(\mathrm{NO})^{-}\right)$ & Non carcinogens & $/$ & 1.6 \\
Copper $(\mathrm{Cu})$ & Non carcinogens & $/$ & 0.04 \\
Zinc $(\mathrm{Zn})$ & Non carcinogens & $/$ & 0.3 \\
Selenium $(\mathrm{Se})$ & Non carcinogens & $/$ & 0.005 \\
Arsenic $(\mathrm{As})$ & Carcinogens & 15 & $/$ \\
Chromium $\left(\mathrm{Cr}{ }^{6+}\right)$ & Carcinogens & 41 & $/$ \\
Cadmium $(\mathrm{Cd})$ & Carcinogens & 6.1 & $/$ \\
\hline
\end{tabular}




\subsubsection{Total Health Risk Assessment}

Various chemicals in drinking water, considering their low concentrations, were presumed that their interaction was additive. As a result, total health hazard risk in water can be calculated by Formula (7):

$$
\text { Rtotal }=\text { RT }+ \text { HIT }
$$

$\mathrm{R}$ total-total health risk of toxicants by drinking, annual;

RT - total cancer risk of genetic toxicants by drinking, annual;

HIT-total health risk of non-genetic toxicants by drinking, annual.

\subsection{Data Analysis}

Water quality determinations for various chemicals were performed in the laboratory of Shenzhen CDC, Shenzhen of China. The all data were analyzed descriptive statistically by software program (SPSS 13.0 for windows). There was statistical significance if $P$ value was below to 0.05 .

\section{Results}

\subsection{Water Quality Determination Results of Shenzhen City in 2012}

All detected indexes for 15 kinds of chemicals in drinking water (150 factory water samples and 207 peripheral samples) in 2012 were in accordance with the standard for drinking water quality of PRC (GB5749-2006) except manganese in one factory and peripheral water sample, and nitrate in another peripheral water sample (see Table 3).

\subsection{Health Risk Assessment}

\subsubsection{Non-Carcinogen Risk Assessment}

Total non-carcinogenic risks of the 12 chemicals such as iron, manganese, volatile phenol, cyanide, fluoride, lead, mercury, ammonia nitrogen, nitrate, copper, zinc, selenium, in factory water, were $178.04 \times 10^{-8}$ for adult and $249.96 \times 10^{-8}$ for children, respectively. In peripheral water, they were $363.02 \times 10^{-8}$ for adult and $509.66 \times 10^{-8}$ for children, respectively. Lead possessed the maximum risk in factory while fluoride in peripheral water. It indicated that health risks on non-carcinogenic chemicals for children were much higher than that on adults (see Table 4).

\subsubsection{Carcinogen Risk Assessment}

Table 5 showed that total carcinogenic annual risks of the three contaminants (e.g. arsenic, chromium and cadmium) in factory water were $25.60 \times 10^{-6}$ for adult and $28.51 \times 10^{-6}$ for children, respectively. In peripheral water, they were $23.47 \times 10^{-6}$ for adult and $26.08 \times 10^{-6}$ for children, respectively. Either in factory or in peripheral water, hexavalent chromium was the most dangerous which risk value accounted for close to a half of total carcinogenic risks.

\subsubsection{Health risk Assessment for Shenzhen Municipal Water}

Table 6 indicated that total annual health risks on Shenzhen municipal water 
Table 3. Concentrations of chemical pollutants in Shenzhen drinking water in 2012.

\begin{tabular}{|c|c|c|c|c|c|c|c|}
\hline \multirow[b]{2}{*}{$\begin{array}{l}\text { Chemical } \\
\text { pollutants }\end{array}$} & \multicolumn{3}{|c|}{ Factory water } & \multicolumn{3}{|c|}{ Peripheral water } & \multirow{2}{*}{$\begin{array}{c}\text { The } \\
\text { standard } \\
\text { limit } \\
(\mu \mathrm{g} / \mathrm{L})\end{array}$} \\
\hline & $\begin{array}{l}\text { Number } \\
\text { of samples } \\
\text { (copies) }\end{array}$ & $\begin{array}{c}\text { Median } \\
(\mu \mathrm{g} / \mathrm{L})\end{array}$ & $\begin{array}{l}\text { Range } \\
(\mu \mathrm{g} / \mathrm{L})\end{array}$ & $\begin{array}{c}\text { Number } \\
\text { of samples } \\
\text { (copies) }\end{array}$ & $\begin{array}{c}\text { Median } \\
(\mu \mathrm{g} / \mathrm{L})\end{array}$ & $\begin{array}{l}\text { Range } \\
(\mu \mathrm{g} / \mathrm{L})\end{array}$ & \\
\hline Iron $(\mathrm{Fe})$ & 150 & 19.44 & $2.25-228.10$ & 207 & 49.34 & $0.04-240.00$ & 300 \\
\hline $\begin{array}{l}\text { Manganese } \\
(\mathrm{Mn})\end{array}$ & 150 & 13.05 & $0.25-108.00$ & 207 & 10.96 & $0.03-141.00$ & 100 \\
\hline $\begin{array}{c}\text { Volatile } \\
\text { phenol, VP }\end{array}$ & 150 & 1.05 & $1.00-2.00$ & 162 & 1.06 & $1.00-2.00$ & 2 \\
\hline Cyanide $\left(\mathrm{CN}^{-}\right)$ & 150 & 1.50 & $1.00-10.00$ & 184 & 1.50 & $0.10-2.00$ & 50 \\
\hline Fluoride $\left(\mathrm{F}^{-}\right)$ & 150 & 236.17 & $50.00-430.00$ & 204 & 275.84 & $50.00-870.00$ & 1000 \\
\hline Lead $(\mathrm{Pb})$ & 150 & 2.22 & $0.10-5.00$ & 204 & 2.00 & $0.03-7.00$ & 10 \\
\hline Mercury (Hg) & 150 & 0.087 & $0.025-1.000$ & 204 & 0.072 & $0.025-1.000$ & 1 \\
\hline $\begin{array}{c}\text { Ammonia } \\
\text { nitrogen } \\
\left(\mathrm{NH}_{3}^{-} \mathrm{N}\right)\end{array}$ & 2 & 10.00 & $10.00-10.00$ & 0 & 0 & $0-0$ & 500 \\
\hline Nitrate $\left(\mathrm{NO}_{3}^{-}\right)$ & 150 & 1564 & $20-3250$ & 204 & 1777 & $5-13950$ & 10,000 \\
\hline Copper $(\mathrm{Cu})$ & 150 & 3.18 & $0.50-14.00$ & 204 & 4.04 & $0.05-100.00$ & 1000 \\
\hline Zinc $(\mathrm{Zn})$ & 150 & 15.79 & $0.40-96.00$ & 203 & 29.95 & $0.40-380.00$ & 1000 \\
\hline Selenium (Se) & 150 & 2.08 & $0.50-5.00$ & 204 & 1.53 & $0.09-5.00$ & 10 \\
\hline Arsenic (As) & 150 & 2.09 & $0.50-5.00$ & 204 & 1.62 & $0.04-5.00$ & 10 \\
\hline $\begin{array}{l}\text { Chromium } \\
\left(\mathrm{Cr}^{6+}\right)\end{array}$ & 150 & 3.10 & $2.00-5.00$ & 184 & 3.30 & $2.00-6.00$ & 50 \\
\hline Cadmium (Cd) & 150 & 1.10 & $0.01-2.00$ & 204 & 0.72 & $0.03-5.00$ & 5 \\
\hline
\end{tabular}

Note: the standard limit refers to the standard for drinking water quality of PRC (GB5749-2006).

Table 4. Annual risk for non-carcinogenic materials in Shenzhen municipal water (annual).

\begin{tabular}{ccccc}
\hline \multirow{2}{*}{ Chemicals } & \multicolumn{2}{c}{ Factory water(annual) } & \multicolumn{2}{c}{ Peripheral water(annual) } \\
\cline { 2 - 5 } & adult $\left(\times 10^{-8}\right)$ & children $\left(\times 10^{-8}\right)$ & adult $\left(\times 10^{-8}\right)$ & children $\left(\times 10^{-8}\right)$ \\
\hline Iron $(\mathrm{Fe})$ & 2.88 & 4.04 & 7.31 & 10.26 \\
Manganese $(\mathrm{Mn})$ & 4.14 & 5.81 & 3.48 & 4.88 \\
Volatile phenol, VP & 0.15 & 0.21 & 0.15 & 0.21 \\
Cyanide $\left(\mathrm{CN}^{-}\right)$ & 1.80 & 2.53 & 1.80 & 2.53 \\
Fluoride $\left(\mathrm{F}^{-}\right)$ & 17.48 & 24.54 & 204.40 & 286.96 \\
Lead $(\mathrm{Pb})$ & 70.46 & 98.92 & 63.35 & 88.94 \\
Mercury $(\mathrm{Hg})$ & 12.89 & 18.09 & 10.66 & 14.97 \\
Ammonia nitrogen $\left(\mathrm{NH}_{3}^{-} \mathrm{N}\right)$ & 0.46 & 0.64 & 0.00 & 0.00 \\
Nitrate $\left.(\mathrm{NO})^{-}\right)$ & 43.43 & 60.98 & 49.35 & 69.28 \\
Copper $(\mathrm{Cu})$ & 3.53 & 4.96 & 4.49 & 6.30 \\
Zinc $(\mathrm{Zn})$ & 2.34 & 3.28 & 4.44 & 6.23 \\
Selenium $(\mathrm{Se})$ & 18.48 & 25.95 & 13.60 & 19.09 \\
Total & 178.04 & 249.96 & 363.02 & 509.66 \\
\hline
\end{tabular}


Table 5. Annual risk for carcinogenic materials in Shenzhen municipal water (annual).

\begin{tabular}{ccccc}
\hline \multirow{2}{*}{$\begin{array}{c}\text { Chemical } \\
\text { pollutants }\end{array}$} & \multicolumn{2}{c}{ Factory water(annual) } & \multicolumn{2}{c}{ Peripheral water (annual) } \\
\cline { 2 - 5 } & adult $\left(\times 10^{-6}\right)$ & children $\left(\times 10^{-6}\right)$ & adult $\left(\times 10^{-6}\right)$ & children $\left(\times 10^{-6}\right)$ \\
\hline Arsenic (As) & 8.90 & 10.65 & 7.58 & 9.34 \\
Cadmium (Cd) & 2.69 & 3.63 & 1.82 & 2.49 \\
Total & 25.60 & 28.51 & 23.47 & 26.08 \\
\hline
\end{tabular}

Table 6. Total annual health risk on Shenzhen municipal water.

\begin{tabular}{ccccc}
\hline \multirow{2}{*}{$\begin{array}{c}\text { Chemical } \\
\text { pollutants }\end{array}$} & \multicolumn{2}{c}{ Factory water (annual) } & \multicolumn{2}{c}{ Peripheral water (annual) } \\
\cline { 2 - 5 } & adult $\left(\times 10^{-6}\right)$ & children $\left(\times 10^{-6}\right)$ & adult $\left(\times 10^{-6}\right)$ & children $\left(\times 10^{-6}\right)$ \\
\hline Carcinogens & 25.60 & 28.51 & 23.47 & 26.08 \\
Non carcinogens & 1.78 & 2.49 & 3.63 & 5.09 \\
Total & 27.38 & 31.00 & 27.10 & 31.17 \\
\hline
\end{tabular}

including the 3 genetic toxicants and 12 non-genetic toxicants were $27.38 \times 10^{-6}$ for adult and $31.00 \times 10^{-6}$ for children in factory water, respectively. In peripheral water, they were $27.10 \times 10^{-6}$ for adult and $31.17 \times 10^{-6}$ for children, respectively. The major contributor was the carcinogens for the total risk value. Both off-work water and pipe water made higher health risks to children than that to adults.

\section{Discussion}

Numerous literatures indicate that there have been hundreds kinds of chemical and organic pollutants in drinking water and water sources although concentrations of these contaminants may be low [9] [11]. Some of these possess long biological half-life period, such as lead and cadmium as long as 1460 days and 16 31 years respectively, and have biological accumulation and amplification effects on account of the food chain [12] [13]. It is well known that accumulation of toxic metals etc in the body can cause chronic injuries with long-term intake accompanying with drinking water ingestion. Risk assessment is fundamentally an attempt to quantify the possible health consequences of human exposure to particular circumstances [14]. Environmental health risk assessment on contaminants in drinking water can assess directly water comprehensive quality in response to health risk per one year [2]. According to classification of chemicals administrated by the US EPA, contaminants in drinking water may be subdivided into two main groups, namely genetic toxic and non-genetic toxic substances [3] [4]. Hexavalent chromium, arsenic and cadmium discussed herein belonged to the genetic toxic substance which could cause inherited gene defects and carcinogenicity [12] [13]. The twelve kinds of materials mentioned in this study such as iron, manganese, lead, fluoride, volatile phenol, cyanide, mercury, ammonia nitrogen, nitrate, copper, zinc and selenium, were attributed to the non-genetic toxic compounds which may result in adverse health effects under 
some circumstances because of human exposure. For the genetic toxic pollutants in the produced and peripheral water, its carcinogenic risks derived from this study were $25.60 \times 10^{-6}$ and $23.47 \times 10^{-6}$ per one year for adults, and $28.51 \times 10^{-6}$ and $26.08 \times 10^{-6}$ per one year for children, respectively. Similarly, non-carcinogenic risks based on the non-genetic chemicals in the factory and pipe water were 1.78 $\times 10^{-6}$ and $3.63 \times 10^{-6}$ per one year for adults, and $2.49 \times 10^{-6}$ and $5.09 \times 10^{-6}$ per one year for children, separately. Therefore, as described above, we concluded that the total human health risks including the three kinds of genetic toxic materials and twelve types of non-genetic toxic substances were $27.38 \times 10^{-6}$ (factory water) and $27.10 \times 10^{-6}$ (peripheral water) per one year for adults, and $31.00 \times$ $10^{-6}$ (factory water) and $31.17 \times 10^{-6}$ (peripheral water) per one year for children, respectively. On the basis of the maximum tolerable risk level $\left(5.0 \times 10^{-5}\right.$ per one year)recommended by the International Commission on Radiation Protection (ICRP) [8] [9], Shenzhen water supply is considered to be safe and protective for public health within the scope of risk value.

These results also revealed that among the water pollutants, hexavalent chromium was the most toxic genetic substance and fluoride and lead among the non-genetic toxicants whose harms to human were the most serious. Furthermore, the mean fluoride concentration increased in the process of water allocation from factory to pipe and the mean lead content changed little, which mechanism is still no known and the implications of this should be further explored. In addition, it showed from this study that the genetic toxic chemicals are greater risk comparing with the non-genetic substances, and the rather risk of children than adults. It should be pointed out that, of course, some uncertainty factors should be taken into account, such as only considering drinking water exposed way, representativeness on exposure parameters and characteristics because of different race and living habits between the eastern and western population, and so on [7] [8] [11]. Therefore, it is basic and key for health risk assessment that sensitive detection techniques on water contaminants and database establishment on Chinese exposure parameters and characteristics.

\section{Acknowledgements}

We would like to thank to Department of Environment and Health of Shenzhen CDC for chemical dataset for this study. The authors thank the 10 district CDCs in Shenzhen for water samples collection. Also, we like to thank laboratory of Shenzhen CDC for their collaboration. The authors express their sincere thanks to Dr. Donald G. Barnes for his critical review of the manuscript.

\section{Conflicts of Interest}

The authors declare no conflicts of interest regarding the publication of this paper.

\section{References}

[1] Bempah, C.K., Donkor, A., Yeboah, P.O., Dubey, B. and Oseifosu, P. (2011) A Pre- 
liminary Assessment of Consumer's Exposure to Organochlorine Pesticides in Fruits and Vegetables and the Potential Health Risk in Accra Metropolis, Ghana. Food Chemistry, 128, 1058-1065. https://doi.org/10.1016/j.foodchem.2011.04.013

[2] Biksey, T.M., Schultz, A.C. and Bernhardt, A.M. (2004) Ecological and Human Health Risk Assessment. Water Environment Research, 76, 2510-2567.

https://www.jstor.org/stable/29763717 https://doi.org/10.2175/106143004X145894

[3] Caylak, E. (2012) Health Risk Assessment for Trace Metals, Polycyclic Aromatic Hydrocarbons and Trihalomethanes in Drinking Water of Cankiri, Turkey. Journal of Chemistry, 9, 1976-1991.

[4] Cotruvo, J.A. (1988) Drinking Water Standards and Risk Assessment. Regulatory Toxicology \& Pharmacology, 8, 288-299.

https://doi.org/10.1016/0273-2300(88)90016-5

[5] Ni, F.Q., Liu, G.D., Ren, H.Z., Yang, S.C., Ye, J., Lu, X.Y. and Yang, M. (2009) Health Risk Assessment on Rural Drinking Water Safety-A Case Study in Rain City District of Ya'an City of Sichuan Province. Journal of Water Resource and Protection, 2, 128-135.

[6] Fu, G., Zeng, Q., Zhao, L., Zhang, Y., Feng, B.J., Wang, R., Zhang, L., Wang, Y. and Hou, C.C. (2015) Health Risk Assessment of Drinking Water Quality in Tianjin Based on GIS. Environmental Science, 36, 4553-4560. http://jtp.cnki.net/bilingual/detail/html/HJKZ201512034?view=3

[7] Goldhaber, S.B. (2003) Trace Element Risk Assessment: Essentiality vs. Toxicity. Regulatory Toxicology \& Pharmacology, 38, 232-242.

[8] Hoque, Y.M., Tripathi, S., Hantush, M.M. and Rao, S.G. (2012) Watershed Reliability, Resilience and Vulnerability Analysis under Uncertainty Using Water Quality Data. Journal of Environmental Management, 109, 101-112. https://doi.org/10.4236/jwarp.2009.12017

[9] Kimmel, C.A. (2001) U.S. EPA Reference Dose/Reference Concentration Methodology: Update on a Review of the Process. Human \& Ecological Risk Assessment: An International Journal, 7, 117-123. https://doi.org/10.1080/20018091094231

[10] Ma, J. and Singhirunnusorn, W. (2012) Distribution and Health Risk Assessment of Heavy Metals in Surface Dusts of Maha Sarakham Municipality. Procedia-Social and Behavioral Sciences, 50, 280-293. https://doi.org/10.1016/j.sbspro.2012.08.034

[11] Pinheiro, M.C., Oikawa, T., et al. (2006) Comparative Study of Human Exposure to Mercury in Riverside Communities in the Amazon Region. Brazilian Journal of Medical \& Biological Research, 39, 411-414. https://doi.org/10.1590/S0100-879X2006000300012

[12] Renwick, A.G. (2010) Pesticide Residue Analysis and Its Relationship to Hazard Characterisation (ADI/ARfD) and Intake Estimations (NEDI/NESTI). Pest Management Science, 58, 1073-1082. https://onlinelibrary.wiley.com/doi/abs/10.1002/ps.544

[13] Spickett, J., Katscherian, D. and Yang, M.G. (2012) A New Approach to Criteria for Health Risk Assessment. Environmental Impact Assessment Review, 32, 118-122. https://doi.org/10.1016/j.eiar.2011.06.004

[14] Thompson, C.M., Gaylor, D.W., Tachovsky, J.A., Perry, C., Carakostas, M.C. and Haws, L.C. (2013) Development of a Chronic Noncancer Oral Reference Dose and Drinking Water Screening Level for Sulfolane Using Benchmark Dose Modeling. Journal of Applied Toxicology, 33, 1395-406. https://doi.org/10.1002/jat.2799 